\title{
Microclimate Variations between Semienclosed and Open Sections of a Marathon Route
}

\author{
Paulina Wong, ${ }^{1}$ Poh-Chin Lai, ${ }^{1}$ and Melissa Hart ${ }^{1,2}$ \\ ${ }^{1}$ Department of Geography, The University of Hong Kong, Pokfulam Road, Pokfulam, Hong Kong \\ ${ }^{2}$ Australian Research Council Centre of Excellence for Climate System Science, Climate Change Research Centre, \\ The University of New South Wales, Sydney, NSW 2052, Australia
}

Correspondence should be addressed to Paulina Wong; paulinaw@hku.hk

Received 22 July 2013; Accepted 24 August 2013

Academic Editor: Andreas Matzarakis

Copyright (C) 2013 Paulina Wong et al. This is an open access article distributed under the Creative Commons Attribution License, which permits unrestricted use, distribution, and reproduction in any medium, provided the original work is properly cited.

\begin{abstract}
The Hong Kong Standard Chartered Marathon, held annually, is one of the most popular international marathon events. Its primarily urban environmental setting characterized by high-density urban areas, semienclosed tunnels, and suspension bridges, together with the herds of runners, has an influence on the microclimate along the marathon course. This study focused on assessing and comparing variations in temperature and vapour pressure (vis-à-vis relative humidity) against the crowd of runners, or the herd effects, in two different environmental settings along the marathon course: semienclosed (a tunnel) versus open space (a suspension bridge). A series of small iButtons were deployed at strategic locations along the course to undertake minute-byminute measurements of temperature and relative humidity. It was found that herd effects of varying degrees were present in both semienclosed and open settings. Various environmental differences also played a role in ameliorating or amplifying the climatological effects of the herd of runners. Our study suggests that microclimate variations in different environmental settings and crowd conditions could have an impact on runners. This new knowledge can inform the design of marathon routes. It also establishes the feasibility of employing the iButton logging sensors for widespread deployment and monitoring of meteorological situations.
\end{abstract}

\section{Introduction}

More than 500 marathons are held annually around the world, with competitors ranging from elite marathon runners to recreational athletes [1]. Each marathon is challenging by the way of its course design and the environment through which the route passes. The increased popularity of marathons has prompted research on the effects of weather conditions on runners. Previous studies have been mainly based on statistical analyses of past marathon data by quantifying effects of weather conditions on the performance or completion times of the runners [2-6].

The most noticeable human effect is in the microclimates found in the heavily built-up areas, and this localised microclimate may become more pronounced when runners are tightly bunched in moving packs or "herds" [7, 8]. In addition to anthropogenic impacts on the microclimate from the herds of runners, course terrain, landscape, urban configurations, and meteorological conditions will contribute to the microclimate along a marathon route [9], which may influence level of human thermal comfort [10] and performance of each individual runner. However, there is a lack of studies exploring possible impacts of microclimatic variation along marathon courses, particularly in events held in such challenging conditions as in the Hong Kong urban area.

The Hong Kong Standard Chartered Marathon, one of the signature international sporting events of Hong Kong, is held annually with recorded entrants growing from 1,000 in 1997 to 70,000 in 2012 [11]. The event route is confined to urban areas passing through various types of urban morphology and topography. The route passes through commercial areas with high building density and many built structures which do not usually have pedestrian access, such as enclosed tunnels, divided highways, and overhead bridges.

It is well known that warmer temperatures and higher humidity levels have a negative effect on the runners due to 
the reduction of heat loss and the corresponding increase in the body temperature $[8,12]$. During warm conditions, marathon runners' control of their thermoregulation may be reduced $[5,13]$, and heat loss of runners would physiologically worsen by a parallel increase in the metabolic heat production from exercising under a relatively high ambient temperature. Febbraio [14] suggested that the intramuscular temperature would rise in proportion to the increase of work load and that metabolism rate would also amplify during exercise and under thermal stress. It is common for runners to suffer from heat exhaustion, heat stress, and other heat-related illnesses $[15,16]$. A few young runners collapsed in the middle of the 2012 Hong Kong Marathon run, and one was reported dead [17]. In addition to heating up when exercising, metabolic heat emissions from surrounding people when in a crowd can also affect levels of thermal comfort and/or stress [7].

Blows [7] established the "penguin effect" to illustrate physiological changes on people in overcrowded situations. He argued that overcrowding would reduce the heat loss ability of an individual exercising in a crowd and that the physiological heat stress would amplify if the crowd was to engage in physical or emotionally heightened activities. He also claimed that heat would transfer from people to the environment. A similar study conducted by De Freitas et al. [18] quantified and modelled heat loads brought about by running in a herd. It became evident that the heat load for a runner in an exercising crowd would increase a great deal compared to those running solo. Furthermore, Montain et al. [8] recognised that slower or casual runners compared to elite runners would suffer further performance deprivation in warmer weather. They argued that slower runners would be exposed longer to the environment and would be more likely to run in close proximity to other runners. The situation would mean that they would be running in a microclimate that tended to be warmer than the indicated weather conditions. In this paper, the effects of heat retention on an individual in a moving crowd are described as the "herd effect" which is unlike the "penguin effect" which describes the effects of heat retention on an individual in a stationary crowd.

In view of the likelihood of thermal heat stress arising from exercising in high ambient temperatures and the adverse health impacts caused by excessive heat retention of an individual in a crowd, this study focuses on assessing the above phenomena in semienclosed and open spaces. It offers empirical evidence of the "herd effect" on the microclimate in different environmental settings along a marathon route.

\section{Materials and Method}

2.1. Background and Study Area. Hong Kong has a humid subtropical climate (Köppen classification Cwa) with hot and humid summers and mild winters. Most summer days have high humidity with warm air coming from the southwest, creating local thermal discomfort. The Hong Kong Standard Chartered Marathon is usually held in late winter or early spring to minimise runner discomfort. The full marathon follows its famed urban route starting at Nathan Road in

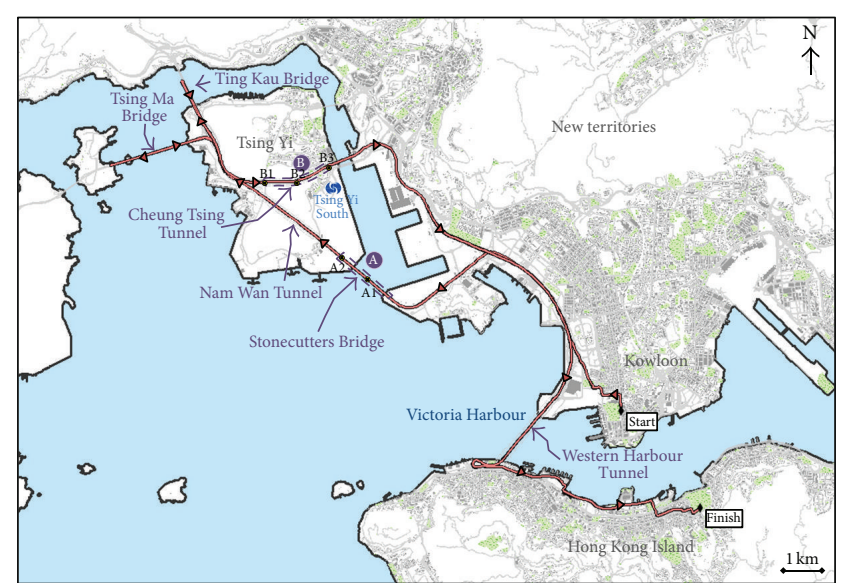

_ Full marathon

Figure 1: The 2012 Hong Kong Standard Chartered Marathon Route with study sites and sampling locations indicated.

Tsim Sha Tsui and finishing at the Victoria Park in Causeway Bay [11] (Figure 1). The course follows major highways and passes through three tunnels (Nam Wan, Cheung Tsing, and Western Harbour) and three bridges (Stonecutters, Tsing Ma, and Ting Kau). In 2012, the marathon was held on 5th February from 0530 to 1300 . The weather on that day was calm with light north-easterly winds and warmer than average air temperature and vapour pressure ranging from $16^{\circ} \mathrm{C}$ to $22^{\circ} \mathrm{C}$ and $13.6 \mathrm{hPa}$ to $25.1 \mathrm{hPa}$, respectively, as reported by the Hong Kong Observatory [19]. Average daily temperatures in February range between $15.0^{\circ} \mathrm{C}$ to $18.9^{\circ} \mathrm{C}$, and mean daily vapour pressure is $15.4 \mathrm{hPa}$ [19].

Two study locations representing an open area (Site A) and a semienclosed space (Site B) (Figure 1 and Table 1) were used to examine variability in thermal environment and microclimate conditions along the marathon course. A camera with a fish-eye lens was employed to take photos at both sites to calculate their sky view factors (SVF) using the RayMan model developed by Matzarakis et al. [20]. Site A is the Stonecutters Bridge, a suspension bridge above water located $8 \mathrm{~km}$ along the marathon route. It is totally exposed without vegetation coverage (SVF $=0.97$ for visible sky, Table 1). Site B is the Cheung Tsing Tunnel, $24 \mathrm{~km}$ into the marathon route; the site is a borne tunnel through solid granite of Tsing Yi Island. The $1.6 \mathrm{~km}$ long semienclosed tunnel (SVF $=0$ for no visible sky, Table 1) carries three lanes of dual carriageway and is connected by an overpass at one end and a bridge at the other [21].

Two types of data were collected at these sites: meteorological data and runner counts.

2.2. Meteorological Data. To monitor microclimatic conditions, dry-bulb temperature and relative humidity were monitored using a wireless temperature measuring system, the Thermochrons iButton (type DS1923; Maxim/Dallas Semiconductor Corp., USA). The iButton is a small and durable temperature/humidity sensor equipped with a data logger 
TABLE 1: Urbanisation characteristics of the sampling sites with respect to the marathon route.

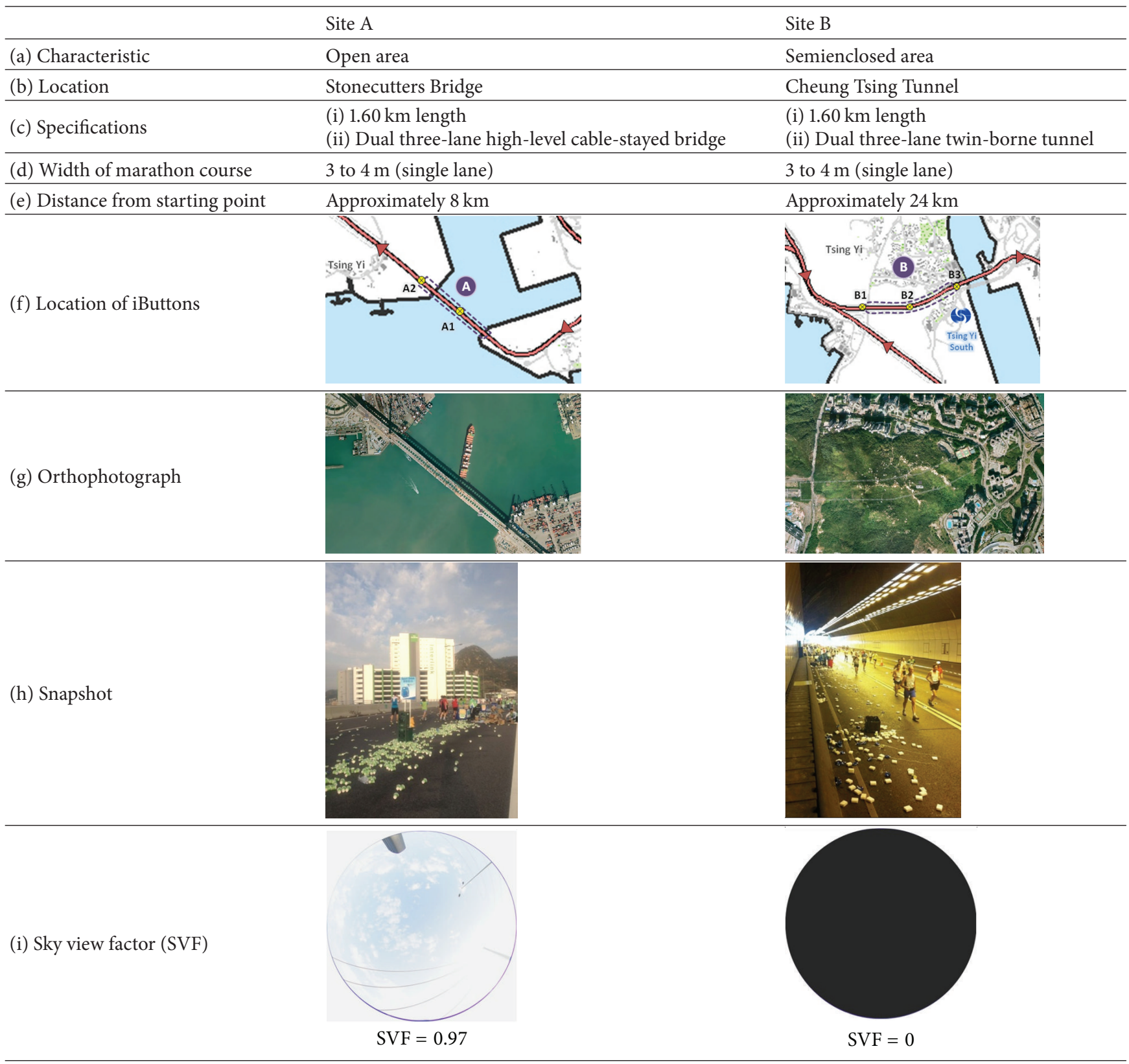

(Figure 2(a)). The thermal and relative humidity accuracy stated by its manufacturer are $\pm 1^{\circ} \mathrm{C}$ with thermal response time of 130 seconds and $\pm 5 \%$ with a 30 -second response time, respectively. All iButtons have been calibrated and tested in house, utilizing ice and warm water baths to assure that all of the iButtons were within $\pm 1^{\circ} \mathrm{C}$ accuracy. Notably, most of them were within $\pm 0.5^{\circ} \mathrm{C}$, which was well within the stated accuracy. Two iButtons (A1 and A2) were installed at Site A. $\mathrm{A} 1$ is at the middle of the bridge which is an entirely open area above water (Figure 3(A1)). A2, on the other hand, is on the landward side and partially surrounded by high-rise buildings on both sides (Figure 3(A2)). Due to the complexity of the semienclosed tunnel microclimate, three iButtons (B1, B2, and B3) were placed at Site B. B1 is at the entrance of the tunnel with lush vegetation alongside the overpass (Figure 3(B1)), site B2 is located in the middle of the tunnel (Figure 3(B2)), and site B3 is located near the exit of the tunnel leading to a suspension bridge which was entirely exposed (Figure 3(B3)). There are jet fans installed along the ceiling of the tunnel for longitudinal ventilation.

Each of the iButtons was housed in an Onset HOBO RS3 solar radiation shield and installed on a standard onemetre high traffic cone (Figure 2(b)). The sensors were set to measure air temperature and relative humidity at one-minute intervals. In addition, one-minute meteorological data were obtained from the nearby Tsing Yi South automatic weather station (see Figure 1). The weather station is managed by the Hong Kong Observatory (HKO) and was classified by Siu 


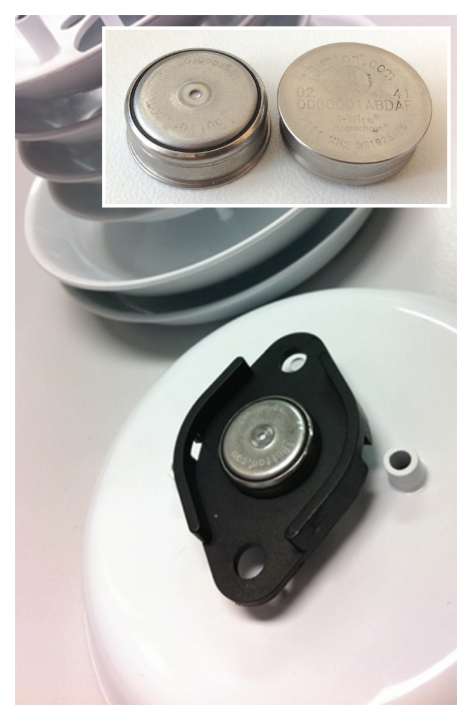

(a)

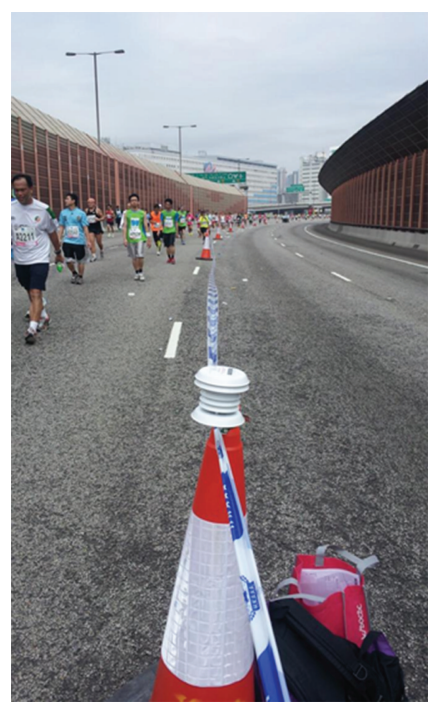

(b)

FIgURE 2: Temperature and relative humidity measurement and logging equipment: (a) iButton in solar radiation shield and (b) iButton in solar radiation shield installed on a traffic cone.

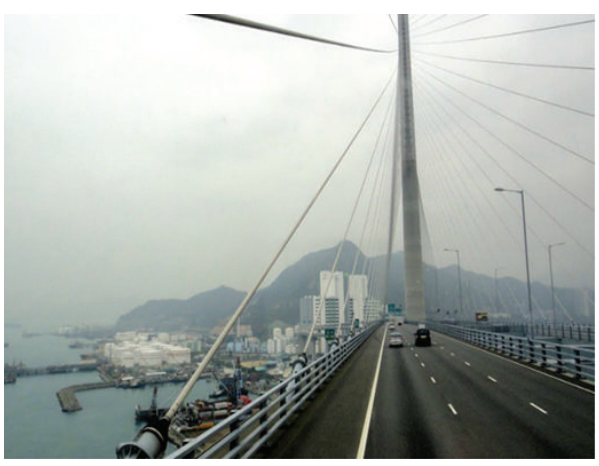

(A1) The $1.6 \mathrm{~km}$ long Stonecutters Bridge is a suspension bridge surrounded by open water on both sides

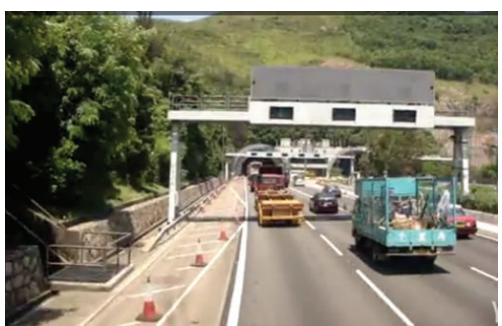

(B1) Entrance to the Cheung Tsing Tunnel is surrounded by green vegetation on both sides

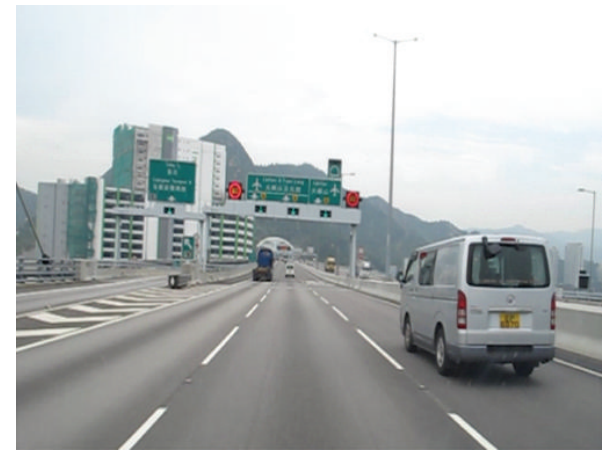

(A2) Exit of the Stonecutters Bridge is surrounded by buildings on both sides before approaching a tunnel

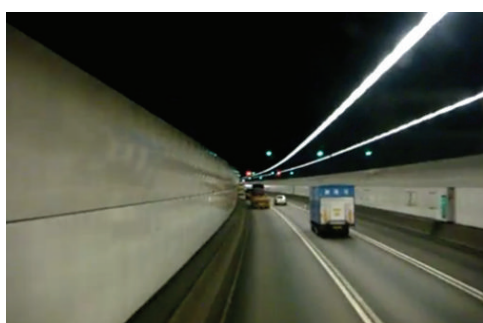

(B2) The $1.6 \mathrm{~km}$ long Cheung Tsing Tunnel is equipped with jet-fan longitudinal ventilation

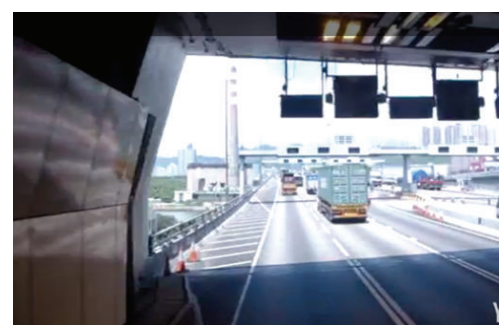

(B3) Exit of the Cheung Tsing Tunnel leads to a suspension bridge that is totally exposed

Figure 3: Photographs and descriptions of each of the sampling locations (A1, A2, B1, B2, and B3).

and Hart [22] as open-set blocks (BCZ5) using the Local Climate Zones (LCZ) landscape classification system [23]. These official measurements were used as a control against data collected by the iButtons.
2.3. Runner Counts. There were a total of 12,105 recorded entrants for the full marathon in 2012 [11]. Staggered start times at 0645 and 0715 were used to manage the large number of runners. Several timing mats were positioned 
by the marathon organisers at split or turning points to track runners throughout the race. The temporal accounts of individual runners were used to model the herds of runners at various junctures to correlate with microclimate data at the corresponding time intervals.

2.4. Method of Analysis. One-minute temperature $\left(T_{\mathrm{IB}}\right)$ and humidity $\left(\mathrm{RH}_{\mathrm{IB}}\right)$ readings collected by iButton sensors at Site A (open space) and Site B (semienclosed space) were compared against the corresponding one-minute HKO meteorological data measured at the Tsing Yi South weather station ( $T_{\mathrm{HKO}}$ and $\mathrm{RH}_{\mathrm{HKO}}$ ) to develop the temperature differences $\left(\Delta T=T_{\mathrm{IB}}-T_{\mathrm{HKO}}\right)$. The temperature differences of each location were then plotted across the temporal scale at a one-minute interval. The herds of runners for the same time period were modelled from the time records of individual runners based on the available runner counts data. With the aid of global positioning system devices, the runner counts were mapped against the temporal scale to examine the herd effects at each site, which have two very different environmental settings.

The humidity readings were used to compute vapour pressure (VP), an absolute measure of atmospheric moisture that is not temperature dependent. The computed vapour pressures were compared across the computed official HKO data to develop the vapour pressure differences $(\triangle \mathrm{VP}=$ $\mathrm{VP}_{\mathrm{IB}}-\mathrm{VP}_{\mathrm{HKO}}$ ). The vapour pressure differences of each site were plotted across the temporal scale of per-minute interval and correlated with the herd of runners to examine the herd effects on atmospheric moisture level under the different environmental settings.

Microclimatic conditions (temperature and vapour pressure) at the two sites were also compared for two groups, herd and no herd, using Student's $t$-test for further verification of the herd effect on microclimatic conditions. Temporal intervals with more than 10 runners (arbitrarily set for this study) were put into the group with herd and the remaining into the group with no herd. This grouping effectively preempted the few elite runners and the very slow runners from skewing the results.

\section{Results}

3.1. Site A-Stonecutters Bridge (Open Space). The marathon commenced at 0645 with runners coming through the measurement sites at Stonecutters Bridge $(8 \mathrm{~km}$ from the starting point) from 0717 to 0830 (Figure 3). Figure 4 illustrates the temperature difference between the iButton readings $\left(T_{\mathrm{IB}}\right)$ and the official temperature readings $\left(T_{\mathrm{HKO}}\right)$ from the Tsing Yi South weather station. Sites A1 (orange line) and A2 (green line), located at the middle and near one end of the $1.6 \mathrm{~km}$ long suspension bridge, respectively, experienced similar trends, with A2 experiencing, on average, a $0.2^{\circ} \mathrm{C}$ higher temperature difference to the control site. Figure 4 also shows two batches of full marathon runners with staggered start times peaking at the Stonecutters Bridge site at 0730 and 0810. Between 0723 and 0740 and 0800 and 0817, the herds of runners crossing the bridge amounted to more than
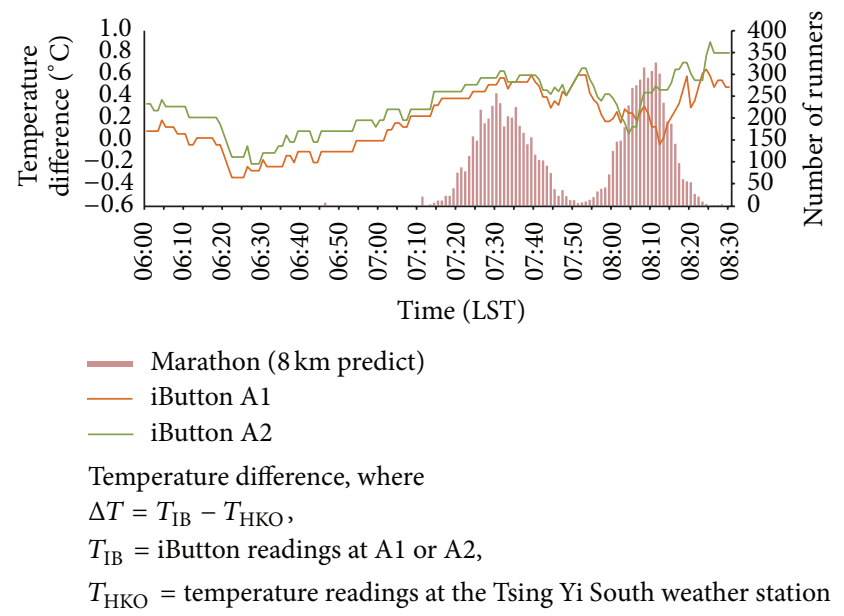

FigURE 4: Minute-by-minute temperature difference and runner counts at the Stonecutters Bridge (Site A: open space).

100 per minute. The temperature difference was on average $0.5^{\circ} \mathrm{C}$ when the first herd of runners were crossing the bridge; this difference narrows after the sun had risen at 0700 . The temperature difference for the second herd of runners was less with an average of $0.3^{\circ} \mathrm{C}$.

The microclimatic conditions at the Stonecutters Bridge were examined under two scenarios: herd and no herd. As defined in Section 2.4, temporal intervals with more than 10 runners were added to the "herd" group, and the remaining intervals fell into the group "no herd". The results of Student's $t$-test in Table 2 reveal significant temperature differences $(P=0.00)$ in the microclimate of both sites when runners pass by. Both $\mathrm{A} 1$ and $\mathrm{A} 2$ reported mean temperature differences of $0.2^{\circ} \mathrm{C}$ higher, during times the herd was passing by.

Figure 5 shows the minute-by-minute vapour pressure differences derived with relative humidity readings from the iButtons $\left(\mathrm{VP}_{\mathrm{IB}}\right)$ and the Tsing Yi South weather station $\left(\mathrm{VP}_{\mathrm{HKO}}\right)$. The line graphs of both $\mathrm{A} 1$ (orange line) and $\mathrm{A} 2$ (green line) at the middle and exit of the suspension bridge, respectively, displayed similar fluctuations. However, vapour pressure difference at A2 was on average $0.4 \mathrm{hPa}$ higher than A1. During the times the first herd of runners crossed Stonecutters Bridge the vapour pressure difference was more pronounced at A2, with an average difference of $0.5 \mathrm{hPa}$, compared to $0.1 \mathrm{hPa}$ at $\mathrm{A} 1$ when the first herd of runners crossed the bridge. The vapour pressure difference for both $\mathrm{A} 1$ and A2 rose sharply (an average of $0.5 \mathrm{hPa}$ and $0.8 \mathrm{hPa}$, resp.) when the second herd passed.

Results of Student's $t$-test, shown in Table 2, revealed significant vapour pressure differences as the herd passed at A2 $(P=0.00)$, which is situated at one end of the suspension bridge, but not at $\mathrm{Al}(P=0.05)$ which is located in the middle of the $1.6 \mathrm{~km}$ long crossing. A mean vapour pressure difference of $0.2 \mathrm{hPa}$ higher with herd was observed at A2 (the landward side) compared with $0.1 \mathrm{hPa}$ at $\mathrm{Al}$ (in the middle of the bridge) indicating the ameliorating effects of open-air circulation. 


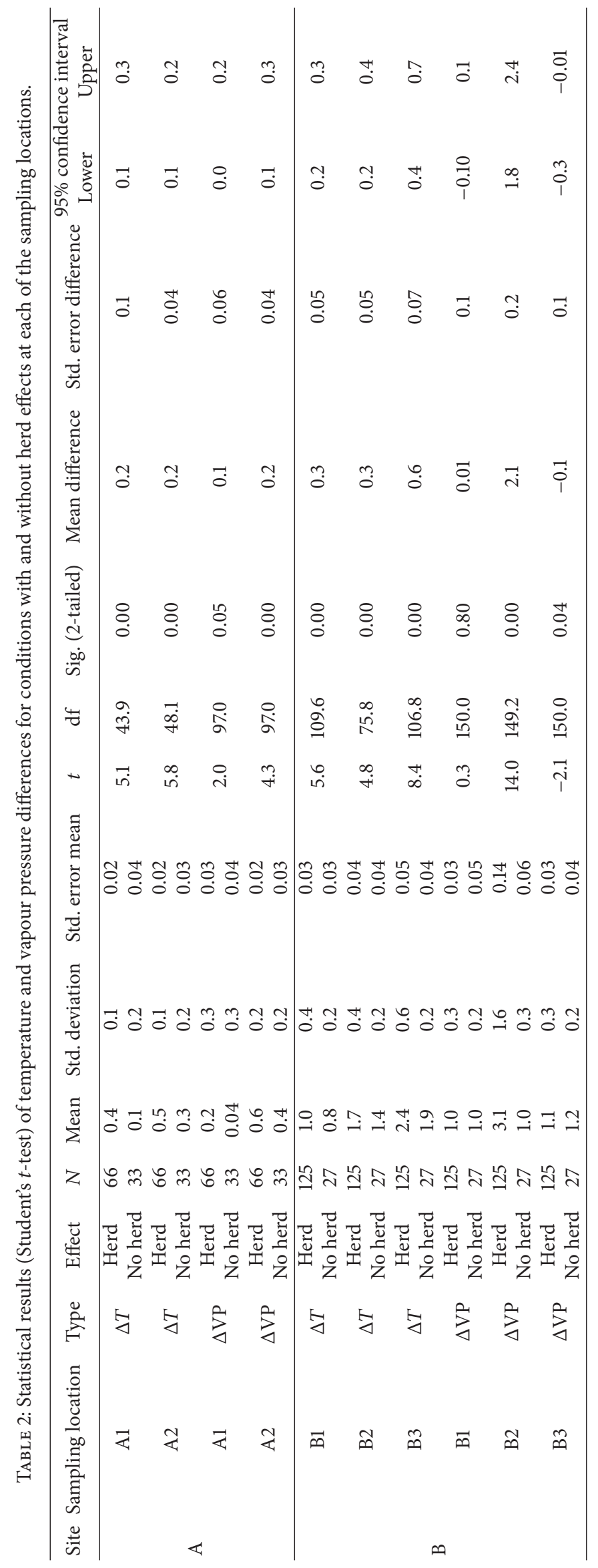




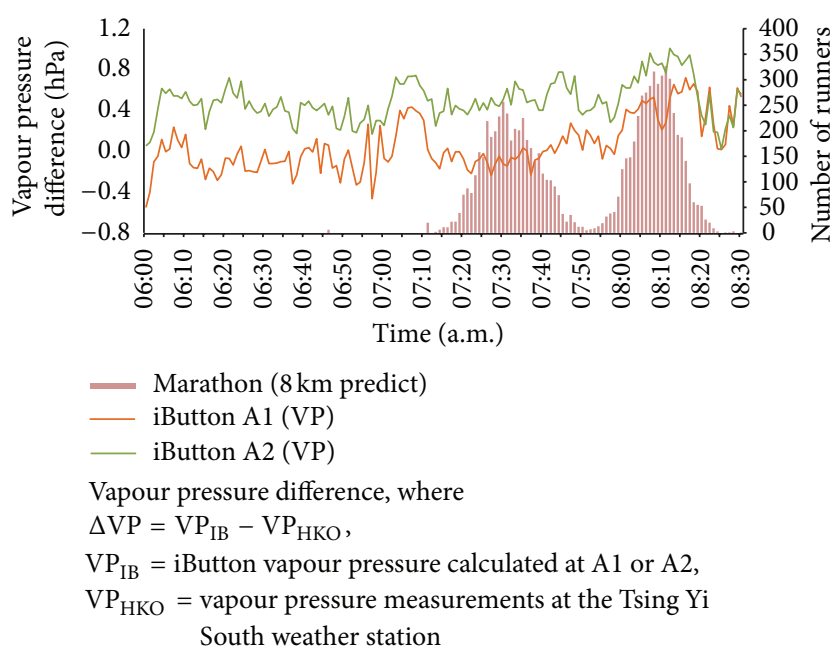

FIGURE 5: Minute-by-minute vapour pressure difference and runner counts at the Stonecutters Bridge (Site A: open space).

3.2. Site B-Cheung Tsing Tunnel (Semienclosed Space). The iButtons B1, B2, and B3 were located at the entrance, centre, and exit of the Cheung Tsing Tunnel as shown in Table 1. The iButton measurements commenced from 0700 until 1030. Figure 6 shows the minute-by-minute temperature difference between the iButtons $\left(T_{\mathrm{IB}}\right)$ and official temperature $\left(T_{\mathrm{HKO}}\right)$ readings from the Tsing Yi South weather station. The three lines (red for B1, green for B2, and purple for B3) registered dissimilar trends with B3, at the exit point of the tunnel, measuring the highest temperature difference (average = $2.3^{\circ} \mathrm{C}$ ), compared to an average of $1.6^{\circ} \mathrm{C}$ for $\mathrm{B} 2$ at the centre of the tunnel and $1.0^{\circ} \mathrm{C}$ for $\mathrm{B} 1$ at the entrance of the tunnel. Figure 6 shows that two herds of runners passed through the Cheung Tsing Tunnel, showing the influence of the staggered start times. It was also evident that, between 0915 and 0935 , some runners from the first herd had begun to slow down to merge with the faster runners of the second herd; the tunnel is more than half way $(24 \mathrm{~km})$ into the $42 \mathrm{~km}$ full marathon run. Time intervals with herds of runners exceeding 100 per minute appeared intermittently between 0945 and 1005 .

Given that the Cheung Tsing Tunnel has jet fans installed along the tunnel ceiling for longitudinal ventilation [21, 24], temperature differences at the centre of the tunnel (B2) displayed a decreasing trend in the presence of runners to indicate that the ventilation system may have done its job in regulating the airflow. The jet fans regulate airflow along one direction to evacuate air pollutants and heat to the end of the tunnel [25]. The situation was quite different at the ends of the tunnel. Before the first herd of runners approached the tunnel starting from 0750, the temperature difference at the centre of the tunnel (B2) was on average $1.4^{\circ} \mathrm{C}$ higher than those at the two ends (B1 and B3). The entrance to the tunnel (B1), unlike the exit (B3), experienced a drop in temperature for the first 40 minutes when total runners per minute stayed below 40. Thereafter, the temperature differences for both entrance (B1) and exit (B3) fluctuated in the same patterns, with $\mathrm{B} 3$ on average $1.0^{\circ} \mathrm{C}$ higher than $\mathrm{B} 1$. The temperature differences appeared to oscillate with the number of runners

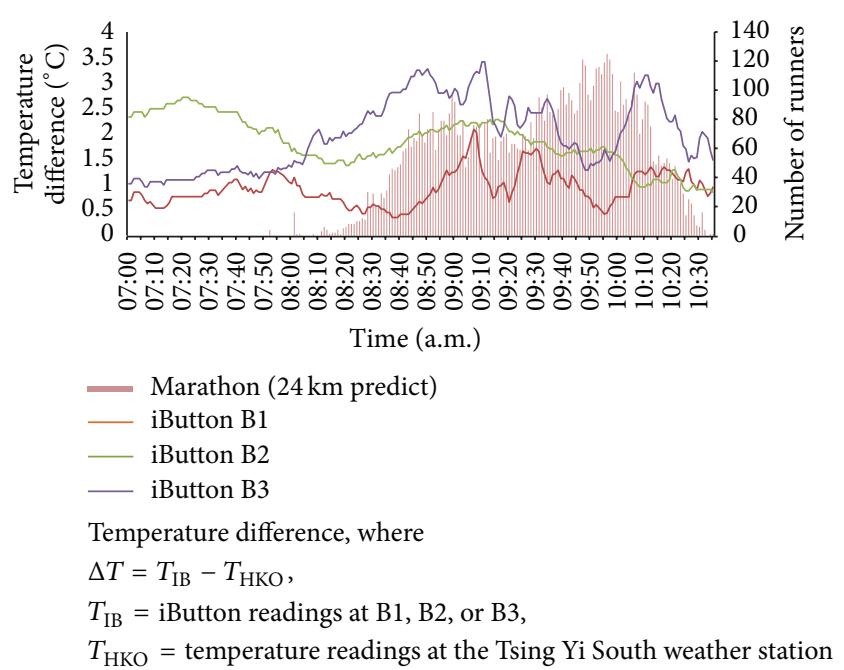

Figure 6: Minute-by-minute temperature difference and runner counts at the Cheung Tsing Tunnel (Site B: semienclosed space).

for the major part of the marathon, except around the second peak of runner counts. We attribute this anomaly to the ventilation control in the tunnel that could have ventilated the airflow to this end and disrupted the herd effect.

The microclimatic conditions in the Cheung Tsing Tunnel were examined under two scenarios: herd and no herd. Results in Table 2 confirmed significant temperature differences $(P=0.00)$ at all three sites during times with herd and no herd. When the sites were under the influence of the herd effect, mean temperature differences of $0.3^{\circ} \mathrm{C}, 0.3^{\circ} \mathrm{C}$, and $0.6^{\circ} \mathrm{C}$ higher were observed for $\mathrm{B} 1, \mathrm{~B} 2$, and $\mathrm{B} 3$, respectively.

Figure 7 illustrates that the vapour pressure differences for all three sampling sites (B1 at the entrance, B2 at the centre, and B3 at the exit) of the tunnel exhibited similar trends and values before the first herd of runners approached the tunnel. Site B2, at the centre of the tunnel, measured a steady increase in vapour pressure as the first herd of runners entered the tunnel at around 0830. The vapour pressure difference continued to rise for 25 minutes from $1.5 \mathrm{hPa}$ to the maximum of $6.0 \mathrm{hPa}$. The vapour pressure declined thereafter as the second herd of runners were leaving the tunnel. Comparable differences with average values of $0.9 \mathrm{hPa}$ and $1.0 \mathrm{hPa}$ higher than the official readings were found at both ends of the tunnel at B1 and B3. There was no remarkable fluctuation at $\mathrm{B} 1$ and $\mathrm{B} 3$ in the presence of runners.

The results of the $t$-test in Table 2 confirmed that there were significant differences in vapour pressure with herd and no herd at B2 $(P=0.00)$ and B3 $(P=0.04)$ located at the centre and exit of the tunnel, with a mean difference in vapour pressure of 2.1 and $-0.1 \mathrm{hPa}$, respectively. No significant difference was observed at B1 located at the entrance of the tunnel, with mean vapour pressure differences of $0.01 \mathrm{hPa}$ $(P=0.80)$, with herd.

\section{Discussion}

Our study offers empirical evidence about the microclimatic differences between semienclosed and open sections 


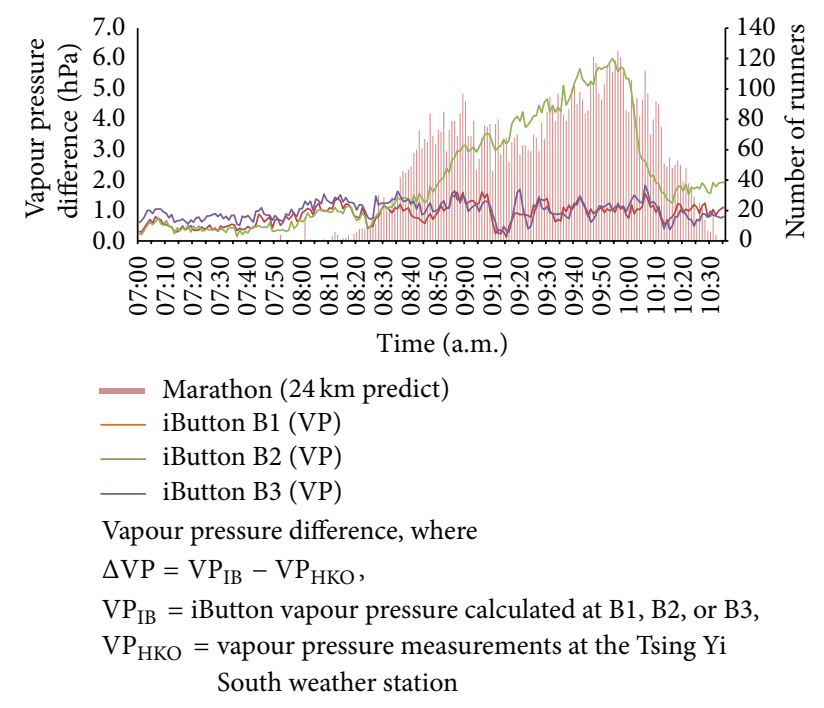

FIgURE 7: Minute-by-minute vapour pressure difference and runner counts at the Cheung Tsing Tunnel (Site B: semienclosed space).

of a marathon route. Herd effects were felt in both settings, with the effects in the semienclosed setting interrupted by controlled ventilation in the tunnel. It does appear that environmental differences have an impact on ameliorating or amplifying the herd effects. For Site A, representative of the entirely open sections of the route (as illustrated in Figures 4 and 5), both temperature and vapour pressure differences for the site located at the end of the bridge (A2) were higher compared to those at Site A1, located at the middle of the bridge. A1 at the middle of the Stonecutter Bridge is an entirely open area above water and has abundant air circulation to offset the herd effects (Figure 3(A1)). A2, on the other hand, is partially surrounded by high-rise buildings to compromise wind ventilation (Figure 3(A2)). Herd effects were, therefore, more pronounced at A2 than A1. In other words, sufficient wind ventilation and proximity to a large water body (serving as a cool sink) effectively reduce both microclimatic urbanisation effects at pedestrian level [26] and herd impacts on the runners.

The situation of $\mathrm{B} 3$ at the exit of the semienclosed tunnel (Figure 3(B3)) is comparable to that of A2 near the end of the overhead bridge. Figures 6 and 7 showed that temperature and vapour pressure differences at B3 were always above those at B1 (entrance of the tunnel). The former led to a suspension bridge which was entirely exposed (Figure 3(B3)), while the latter had lush vegetation alongside the motorway (Figure 3(B1)), demonstrating cooling effects of vegetation on the microclimate $[27,28]$. It is also interesting to note that the ventilation system of the tunnel may have played a role in moderating temperature differences but not in reducing vapour pressure arising from the herds, as illustrated in Figures 6 and 7. The increased airflow from the ventilation system may have caused evaporative cooling of the initial warm, moist air mass brought into the tunnel by the herd of runners. Ventilation systems of this type are designed to evacuate air pollutants (traffic emissions) and heat within the tunnel as means of air quality and fire safety measure [25]. During normal traffic conditions in tunnels of this kind, the airflow from the ventilation fans flows in the direction of prevailing traffic, and the system may occasionally switch off to self-ventilate by taking advantage of traffic-induced piston effects [24]. One major limitation of this study is that we were unable to gain explicit information on the operation of the system during the event, making it difficult to quantify the exact effects of the ventilation system on the herd.

Our study also confirms the practical utility of the small and low-cost iButtons for widespread deployment. The affordable iButtons offer reliable measurement and consistent performance when compared against official readings from a nearby $\mathrm{HKO}$ weather station. Similar to a study by Cheung et al. [29], the accuracy of iButtons in our study was well within $\pm 1^{\circ} \mathrm{C}$ as listed by the manufacturer.

We note a few methodological drawbacks in our study. Firstly, we made use of meteorological data from a nearby weather station managed by the HKO to compute microclimate differences. However, we were unable to separate clearly herd effects from the diurnal warming effects after sunrise at 0700. Secondly, we modelled runner counts from temporal accounts of individual runners. The derived values might not be entirely accurate as $27.8 \%$ of full marathon runners were miscounted for various reasons. For instance, some runners started after the cutoff time, or they did not step on the timing mats properly, or they pulled at the event at some point along the course. In addition, the modelling procedure for runner counts at one-minute time interval assumed that individual runners ran at steady speeds without provisions for stopping for replenishment or relaxation. And finally, the lack of information available to us on the operation of the ventilation system in the tunnel during the event makes it difficult to quantify its impact on the herd of runners; future studies of this kind would benefit from the incorporation of wind speed and wind direction measurements at sampling locations. Despite these limitations, results of our study did suggest that environmental factors and herd effects will affect the microclimate of a marathon course, which may detrimentally impact marathon runners although the error limits of the iButton temperature sensors $\left( \pm 1^{\circ} \mathrm{C}\right)$ should be taken into account during the interpretation of the results.

\section{Conclusion}

This study presented empirical evidence of the "herd effect" on marathon runners and contrasted the microclimate variations of herd effects in two different environmental settings along a full marathon course: open-space suspension bridge (Site A) versus semienclosed vehicle tunnel (Site B).

The microclimate differences at both sites, in terms of temperature and vapour pressure, with and without the influence of the herd of runners were statistically significant. Comparatively, the microclimate differences appeared to be more pronounced at the exits of both sites (A2 and B3). Environmental factors such as greenery, wind ventilation, water body, urban morphology, and mesoscale flows also play a role in impacting the magnitude of the herd effect. 
Although our findings on herd effects may not be exact, the study is the first of its kind to examine association between microclimate differences and crowding of runners. It also demonstrates methodological feasibility for bulk installation of an economical monitoring device for temperature and humidity measurements. Our findings also provide guidance to marathon organisers about design considerations for an optimum marathon course and the need for crowd control to minimise the impact of herd effects.

\section{Conflict of Interests}

The authors declare that there is no conflict of interests regarding the publication of this paper.

\section{Acknowledgments}

The authors would like to acknowledge support from organisers of the Hong Kong Standard Chartered Marathon and the Hong Kong Amateur Athletic Association (HKAAA). Thanks are also extended to the Hong Kong Observatory (HKO). This paper was funded through the University of Hong Kong Hui Oi Chow Trust Fund-General Award (Project no. 201103172004) and the General Research Fund (Project no. 746210) from the Research Grants Council of Hong Kong.

\section{References}

[1] D. M. D. Webner, "Study Done In Marathon Runners Gets National Recognition," The Journal of Crozer-Keystone Healthplex, 2012, http://www.crozerkeystone.org/news/Publications/ The-Journal/2012/december/study-done-in-marathon-runners -gets-national-recognition/.

[2] M. R. Ely, S. N. Cheuvront, and S. J. Montain, "Neither cloud cover nor low solar loads are associated with fast marathon performance," Medicine and Science in Sports and Exercise, vol. 39, no. 11, pp. 2029-2035, 2007.

[3] M. R. Ely, S. N. Cheuvront, W. O. Roberts, and S. J. Montain, "Impact of weather on marathon-running performance," Medicine \& Science in Sports \& Exercise, vol. 39, no. 3, pp. 487493, 2007.

[4] L. M. Trapasso and J. D. Cooper, "Record performances at the Boston marathon: biometeorological factors," International Journal of Biometeorology, vol. 33, no. 4, pp. 233-237, 1989.

[5] T. Vihma, "Effects of weather on the performance of marathon runners," International Journal of Biometeorology, vol. 54, no. 3, pp. 297-306, 2010.

[6] Z. Suping, M. Guanglin, W. Yanwen, and L. Ji, "Study of the relationships between weather conditions and the marathon race, and of meteorotropic effects on distance runners," International Journal of Biometeorology, vol. 36, no. 2, pp. 63-68, 1992.

[7] W. T. Blows, "Crowd physiology: the 'penguin effect," Accident and Emergency Nursing, vol. 6, no. 3, pp. 126-129, 1998.

[8] S. J. Montain, M. R. Ely, and S. N. Cheuvront, "Marathon performance in thermally stressing conditions," Sports Medicine, vol. 37, no. 4-5, pp. 320-323, 2007.

[9] I. Charalampopoulos, I. Tsiros, A. Chronopoulou-Sereli, and A. Matzarakis, "Analysis of thermal bioclimate in various urban configurations in Athens, Greece," Urban Ecosystems, vol. 16, no. 2, pp. 217-233, 2013.

[10] A. Matzarakis, H. Mayer, and M. G. Iziomon, "Applications of a universal thermal index: physiological equivalent temperature," International Journal of Biometeorology, vol. 43, no. 2, pp. 76-84, 1999.

[11] HKAAA, "Standard Chartered Hong Kong Marathon," 2012, http://www.hkmarathon.com/marathon/eng/home.

[12] Y. Kobayashi, Y. Ando, and S. Takeuchi, "Effects of heat acclimation of distance runners in a moderately hot environment," European Journal of Applied Physiology and Occupational Physiology, vol. 45, no. 2-3, pp. 189-198, 1980.

[13] N. El Helou, M. Tafflet, G. Berthelot, J. Tolaini, A. Marc et al., "Impact of environmental parameters on marathon running performance," PLoS One, vol. 7, no. 5, Article ID e37407, 2012.

[14] M. Febbraio, "Alterations in energy metabolism during exercise and heat stress," Sports Medicine, vol. 31, no. 1, pp. 47-59, 2001.

[15] E. Law, "Marathon runners urged to watch step on health," The Standard, 2011, http://www.thestandard.com.hk/news_detail .asp?pp_cat=11\&art_id $=108182 \&$ sid $=31326326 \&$ con_type $=1 \& d_{\text {_ }}$ str $=20110217 \&$ isSearch $=1 \&$ sear_year=2011.

[16] A. M. Porter, "Marathon running and adverse weather conditions: a miscellany," British Journal of Sports Medicine, vol. 18, no. 4, pp. 261-264, 1984.

[17] A. So, "Tragic End. The Standard," 2012, http://www.thestandard.com.hk/news_detail.asp?pp_cat=30\&art_id=119402\&sid= 35310569\&con_type $=3 \& d_{-}$str $=20120206 \&$ isSearch $=1 \&$ sear year $=2012$.

[18] C. R. De Freitas, N. J. Dawson, A. A. Young, and W. J. Mackey, "Microclimate and heat stress of runners in mass participation events," Journal of Climate \& Applied Meteorology, vol. 24, no. 2, pp. 184-191, 1985.

[19] HKO, “The Hong Kong Observatory Official Website”, 2012, http://www.hko.gov.hk/contente.htm.

[20] A. Matzarakis, F. Rutz, and H. Mayer, "Modelling radiation fluxes in simple and complex environments-application of the RayMan model," International Journal of Biometeorology, vol. 51, no. 4, pp. 323-334, 2007.

[21] A. Tam, "Construction of the cheung ching tunnel," Tunnels and Tunnelling, vol. 29, no. 6, pp. 25-26, 1997.

[22] L. W. Siu and M. Hart, "Quantifying urban heat island intensity in Hong Kong SAR, China," Environmental Monitoring and Assessment, vol. 185, no. 5, pp. 4383-4398, 2013.

[23] I. D. Stewart and T. R. Oke, "Local climate zones for urban temperature studies," Bulletin of the American Meteorological Society, vol. 93, no. 12, pp. 1879-1900, 2012.

[24] J. S. M. Li and W. K. Chow, "Vehicular tunnel ventilation design and application of CFD Air Distribution in Rooms," in Proceedings of the 7th International Conference on Air Distribution in Rooms, Ventilation for Health and Sustainable Environment, 2000.

[25] S. Li, Analysis on the fire safety aspects for tunnels in Hong Kong with mathematical models [Ph.D. thesis], The Hong Kong Polytechnic University, Hong Kong, 2005.

[26] E. Ng, "Policies and technical guidelines for urban planning of high-density cities-air ventilation assessment (AVA) of Hong Kong," Building and Environment, vol. 44, no. 7, pp. 1478-1488, 2009. 
[27] T. Fung and W.-L. Siu, "A study of green space and its changes in Hong Kong using NDVI," Geographical and Environmental Modelling, vol. 5, no. 2, pp. 111-122, 2001.

[28] S. S. Lau, P. Lin, and H. Qin, "A preliminary study on environmental performances of pocket parks in high-rise and highdensity urban context in Hong Kong," International Journal of Low-Carbon Technologies, vol. 7, no. 3, pp. 215-225, 2012.

[29] H. K. Cheung, G. J. Levermore, and R. Watkins, "A low cost, easily fabricated radiation shield for temperature measurements to monitor dry bulb air temperature in built up urban areas," Building Services Engineering Research and Technology, vol. 31, no. 4, pp. 371-380, 2010. 

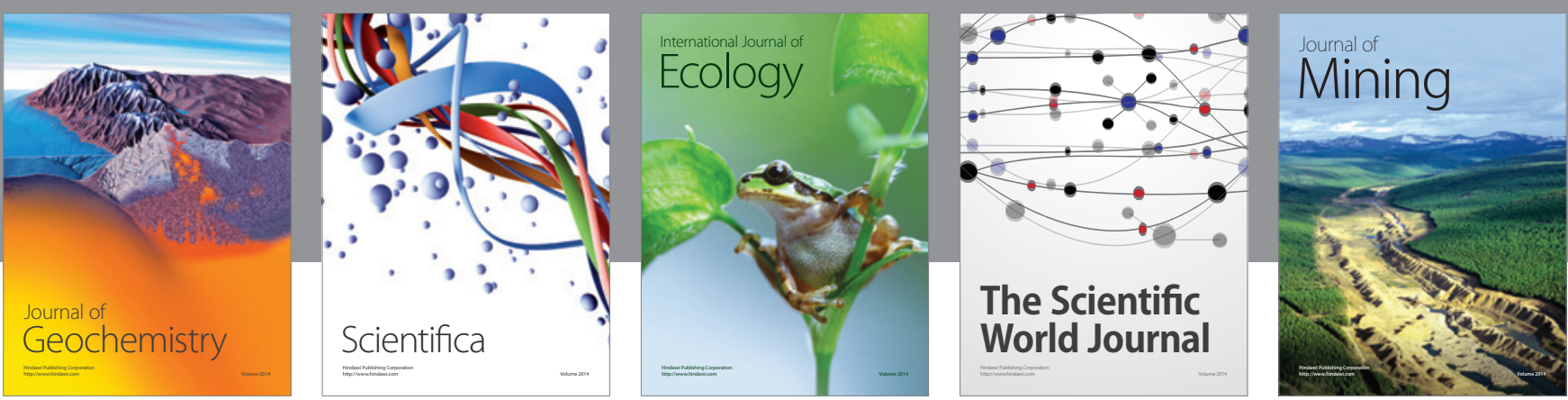

The Scientific World Journal
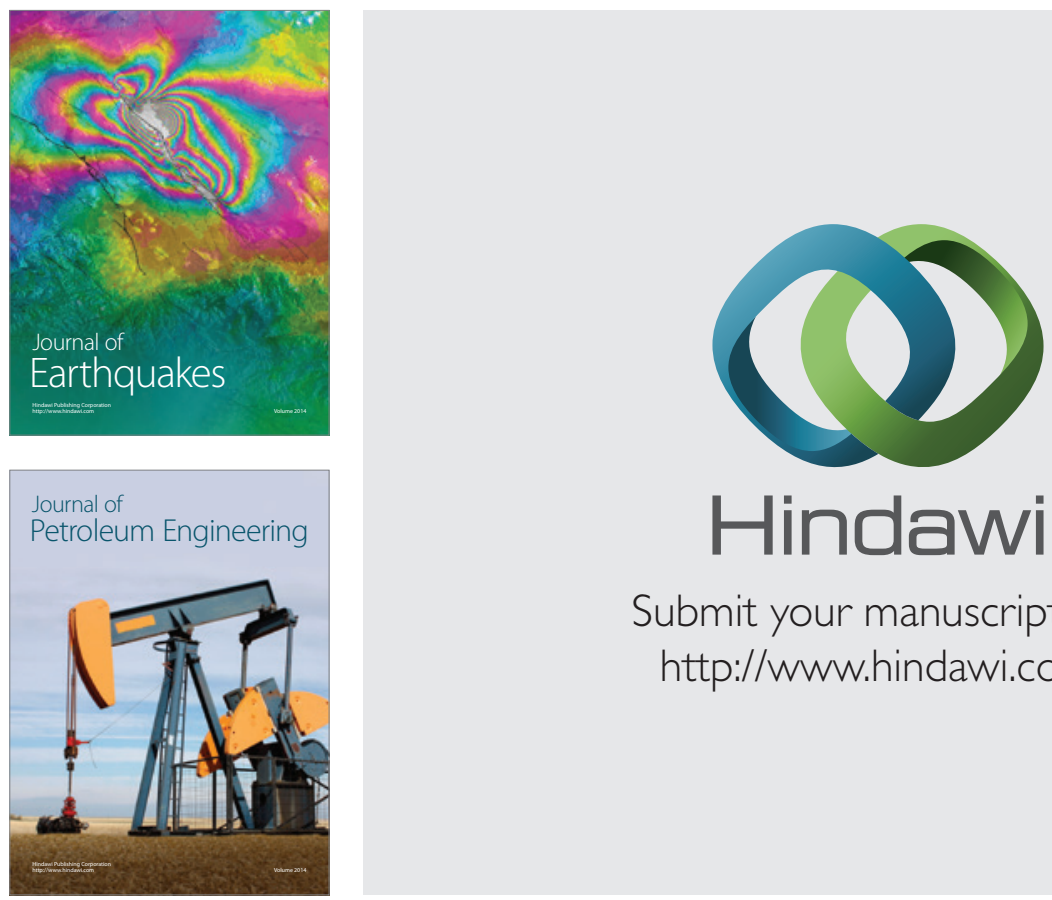

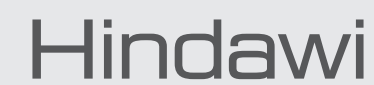

Submit your manuscripts at

http://www.hindawi.com
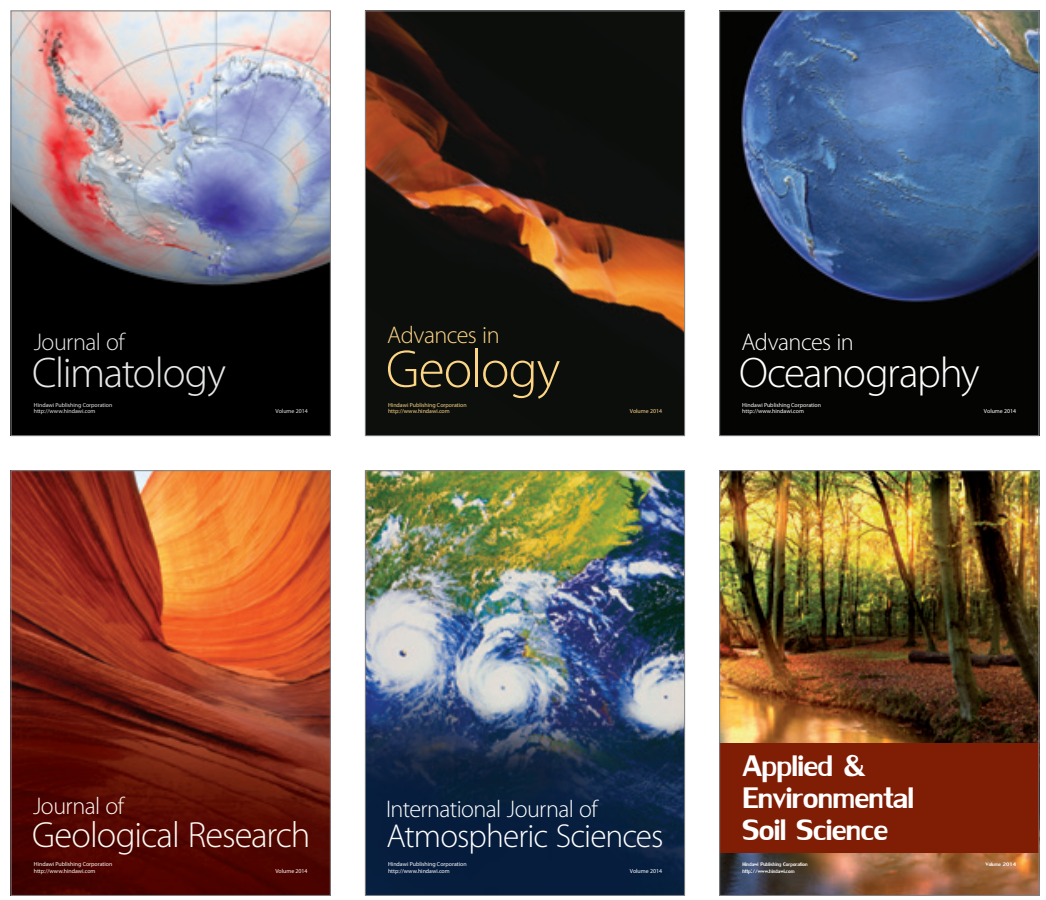
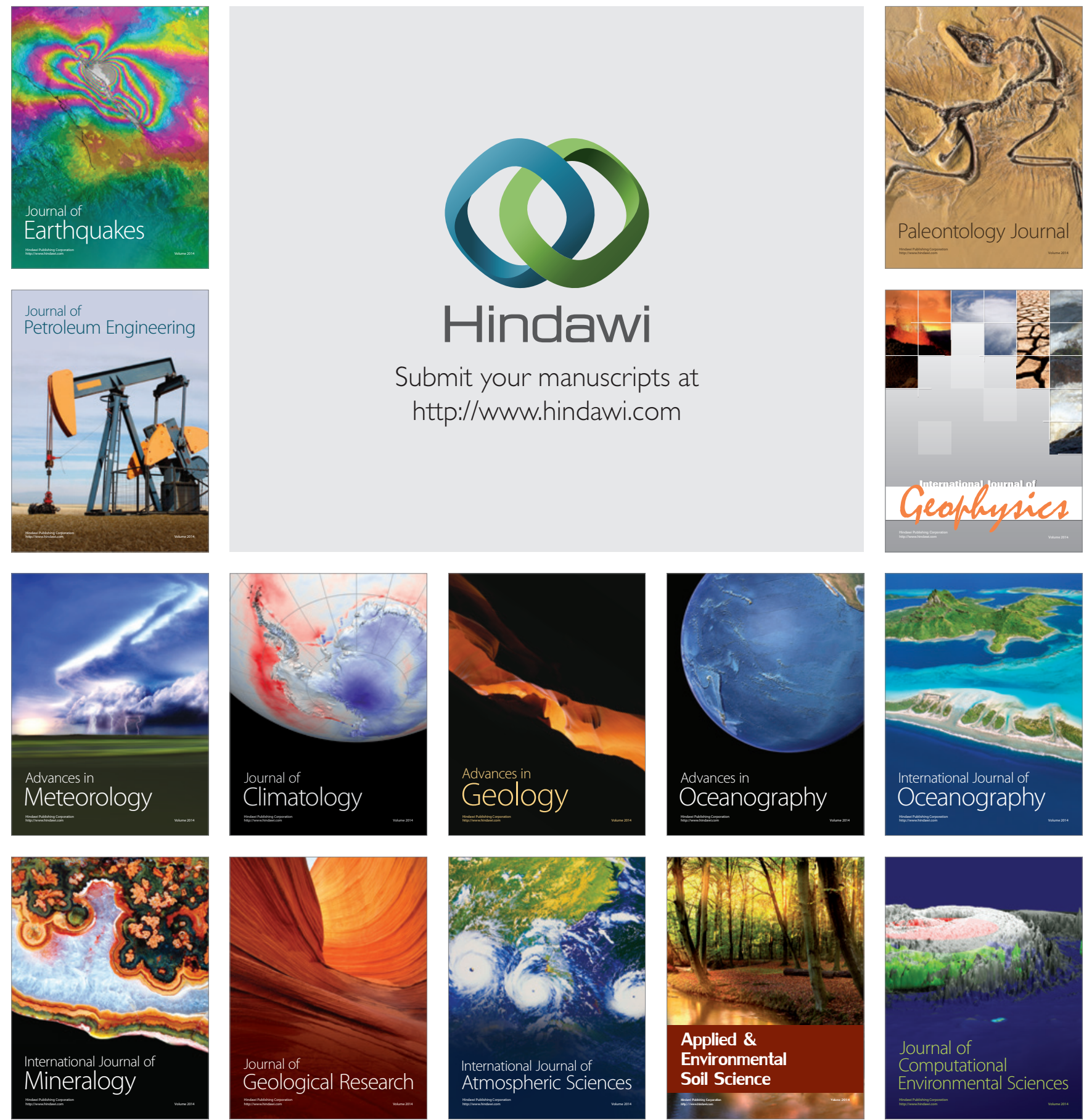